\title{
Presentación \\ La canonización de 1622, la santidad moderna y el potencial de su estudio
}

E

112 de marzo de 1622 se celebró en Roma una canonización que, por muchos motivos, supuso un hito histórico. Aquel día el papa Gregorio XV inscribía en el catálogo de los santos los nombres insignes de san Isidro labrador, san Ignacio de Loyola, san Francisco Javier, santa Teresa de Jesús y san Felipe Neri, «cuatro españoles y un santo» como señaló irónicamente el genio popular romano en la estatua de Pasquino.

Anuario de Historia de la Iglesia, adelantándose a la conmemoración del cuarto centenario de esta canonización múltiple, primera que recogen los anales, ha preparado un cuaderno monográfico, del cual he tenido el honor de ser el coordinador.

Consta este monográfico de ocho trabajos. En el primero de ellos, la profesora Sofía Boesch Gajano realiza un análisis de la historiografía sobre la santidad, que desde hace varias décadas constituye un paradigma de la renovación de los estudios en el campo de la Historia, no solo de la Iglesia, por las amplísimas posibilidades que ofrece. La profesora Boesch, de la Università degli Studi Roma Tre, es una de las principales autoridades a nivel global en el estudio de la santidad y del culto a los santos, especialmente en la época medieval, contando con numerosísimas publicaciones en este campo. En 1996 fundó, con otros estudiosos, la «Associazione italiana per lo studio della santità, dei culti e dell'agiografia» (AISSCA).

El segundo artículo se centra en la reforma de los procedimientos del reconocimiento oficial de la santidad que se llevan a cabo después de Trento y cristalizan fundamentalmente con la erección de la Congregación de Ritos en 1588, a la que se adscribe todo lo relacionado con los procesos de canonización. Otra novedad es el establecimiento de la beatificación. Este periodo de normatividad concluirá en tiempos del papa Urbano VIII con sus famosos decretos para regular el culto público a los siervos de Dios fallecidos con fama de santidad. Giulio So- 
dano, profesor de la Università della Campania «Luigi Vanvitelli», especializado en el estudio de la santidad en el mediodía italiano (cabe recordar su libro Modelli e selezione del Santo Moderno. Periferia napoletana e centro romano), nos ofrece una valiosa síntesis de este periodo crucial para la historia moderna del reconocimiento de la santidad.

A continuación, en el tercer artículo, del que soy autor, nos adentramos ya propiamente en la canonización de 1622, cuya gestación no fue sencilla por cuanto hubo de dar respuesta a diversos intereses espirituales e institucionales que fueron interactuando durante los pontificados de Paulo V y Gregorio XV. Al final, constituyó un ejercicio de fina habilidad diplomática del cual pueden realizarse diversas interpretaciones. Mi propuesta es, precisamente, superar el reduccionismo del mero análisis en clave política para analizar el acontecimiento desde varias perspectivas, singularmente la intra-eclesial, con el fin de observar cómo dicha canonización no lo fue solo de los protagonistas de la Reforma Católica sino, simbólicamente, de la propia Reforma y de sus principales fuerzas operativas.

Los cinco artículos restantes están dedicados a analizar cada uno de ellos a uno de los santos canonizados. Seguimos aquí también el riguroso orden cronológico que se adoptó para la ocasión. Así, el primero de ellos corresponde a san Isidro labrador. María José del Río Barredo, profesora de la Universidad Autónoma de Madrid y autora de numerosas publicaciones sobre la configuración de Madrid como capital de la Monarquía hispana, incluido el papel que desempeñó el Santo labrador en el imaginario colectivo, nos acerca los datos fundamentales del proceso para la beatificación y canonización de quien, paradójicamente, ya recibía culto público desde hacía siglos.

En efecto, san Isidro era el único santo antiguo en esta ceremonia; los otros cuatro eran «santos modernos», recientemente fallecidos. En segundo lugar, fue canonizado san Ignacio de Loyola, fundador de la Compañía de Jesús, cuyo estudio ha sido realizado por el P. Rogelio García Mateo, SI, profesor de la Pontificia Università Gregoriana, centrándose principalmente en el concepto ignaciano de santidad, y por el profesor Javier Burrieza Sánchez, de la Universidad de Valladolid, conocido por sus estudios sobre los jesuitas, quien se ha centrado más específicamente en el iter del proceso de canonización.

Luis Javier Fortún Pérez de Ciriza, profesor de la Universidad Pública de Navarra y Archivero-Bibliotecario del Parlamento de Navarra, es el autor del trabajo dedicado a los procesos de canonización de san Francisco Javier, ofreciendo datos de los dieciséis que se realizaron. No es la primera vez, ni mucho menos, que afronta estudios sobre el misionero navarro, recordándose su valiosa contribución -Una lámpara sobre el candelero- al catálogo de la magna exposición 
celebrada en Pamplona en 2006, «San Francisco Javier en las artes. El poder de la imagen».

El P. Julen Urkiza, OCD, es el autor del trabajo correspondiente a Santa Teresa de Jesús. Nadie mejor que él para realizar esta tarea de síntesis, por cuanto es el editor de los seis voluminosos tomos (con nada menos que 5.500 páginas) de los Procesos de beatificación y canonización de la madre Teresa de Jesús, realizados con motivo del quinto centenario de su nacimiento. Precisamente, en el tomo VI se incluyen todos los documentos relacionados directamente con la ceremonia de 1622, por lo que constituye una valiosísima fuente accesible al investigador.

Por último, Miguel Gotor es el autor del artículo referido a san Felipe Neri. Profesor de la Università degli studi di Torino, es uno de los autores más relevantes en el campo de la santidad moderna, siendo muy valorado su libro I beati del papa. Santità, Inquisizione e obedienza in età moderna. Resulta de gran interés comprobar los motivos por los cuales el santo florentino fue incluido en la canonización, así como el análisis de las estrategias puestas en juego para la promoción de los «santos modernos» por su discípulo y sucesor, y padre de la Historia eclesiástica moderna, el cardenal Baronio.

El objetivo que nos hemos propuesto con la publicación de este cuaderno monográfico sobre la canonización de 1622 no es solo contribuir al análisis de un acontecimiento de gran trascendencia en la Historia de la Iglesia moderna sino, principalmente, abrir nuestra revista a este ingente campo de estudios de la santidad que ya tiene numerosos cultivadores en el ámbito español y americano, al igual que antes en el italiano o el francés, con sus publicaciones, asociaciones, congresos y eventos culturales.

Fermín LABARGA 
